\title{
Efficacy of Itopride in the Prevention of Lubiprostone-Induced Nausea
}

\author{
Tatsuya Abe1, Yoshikazu Hachiro1, Yoshiaki Ebisawa1, Houhei Hishiyama1, \\ Masanori Murakami2, Masao Kunimoto' ${ }^{1}$ \\ ${ }^{1}$ Department of Proctology, Kunimoto Hospital, Asahikawa, Japan \\ ${ }^{2}$ Department of Gastroenterology, Kunimoto Hospital, Asahikawa, Japan \\ Email: t-abe@cf6.so-net.ne.jp
}

Received 28 June 2014; revised 14 August 2014; accepted 29 August 2014

Copyright (C) 2014 by authors and Scientific Research Publishing Inc.

This work is licensed under the Creative Commons Attribution International License (CC BY). http://creativecommons.org/licenses/by/4.0/

cC) (i) Open Access

\section{Abstract}

Background: The efficacy of lubiprostone for chronic constipation has been established through phase III clinical trials. Nevertheless, the continuation of lubiprostone therapy is reportedly difficult due to the development of nausea. The objective of this study is to determine whether the administration of itopride hydrochloride can reduce lubiprostone-related nausea. Methods: Two hundred and thirty-five patients who were receiving lubiprostone ( $24 \mu \mathrm{g}$ capsule twice daily) were enrolled. Seventy-one patients took a prophylactic dose of itopride (50 $\mathrm{mg}$ tablet twice daily) together with lubiprostone to prevent nausea. Thus, the patients were divided into 2 groups: lubiprostone alone (164; control group) and combination therapy with lubiprostone and itopride (71; itopride group). Efficacy measures included changes in constipation scoring system scores, the incidence of treatment-related adverse events including nausea, and the percentage of patients who discontinued treatment within two weeks after administration. Results: Of the 235 patients who were enrolled, 196 were available for analysis. Both treatment groups experienced statistically significant improvements in constipation scoring system scores. The percentage of patients who reported $\geq 1$ adverse event was significantly higher in the control group $(40.9 \%)$ than in the itopride group $(21.9 \%)$. The percentage of patients experiencing nausea was statistically and significantly lower in the itopride group than in the control group $(9.4 \%$ versus $22.7 \%)$. The itopride regimen was also statistically superior compared to the control regimen in terms of treatment discontinuation. Conclusion: The prophylactic administration of itopride can decrease the risk of nausea in patients receiving lubiprostone and consequently reduce the risk of treatment discontinuation.

\section{Keywords}

Chronic Constipation, Itopride, Lubiprostone, Nausea

How to cite this paper: Abe, T., Hachiro, Y., Ebisawa, Y., Hishiyama, H., Murakami, M. and Kunimoto, M. (2014) Efficacy of Itopride in the Prevention of Lubiprostone-Induced Nausea. Open Journal of Gastroenterology, 4, 305-309. 


\section{Introduction}

Chronic constipation (CC) is a common health problem significantly affecting the quality of life of patients and places a burden on the national economy [1]. Management of CC may involve an increased intake of dietary fiber, enemas, and stimulant or osmotic laxatives. Despite the availability of these therapies, approximately $50 \%$ of all patients with $\mathrm{CC}$ are not satisfied with their treatment, a finding primarily attributes to the lack of efficacy [2]. Lubiprostone, a new medication designed for the treatment of CC in both men and women, was approved by the FDA in 2006. The efficacy of lubiprostone in the treatment of constipation has been established in phase III clinical trials [3] [4]. In previous studies, nausea was found to be the most frequent adverse event, affecting up to $31 \%$ of patients receiving lubiprostone. Nausea was mild to moderate in severity in the clinical trials and resulted in treatment discontinuation in $8.7 \%-20 \%$ of patients [5] [6]. Nonetheless, prophylactic therapy of lubiprostone-induced nausea has not been reported. Appropriate use of antiemetic drugs may be crucial for maintaining both compliance and quality of life in patients receiving lubiprostone. The objective of this study is to determine whether the administration of itopride hydrochloride can reduce lubiprostone-related nausea in patients receiving lubiprostone.

\section{Patients and Methods}

We prospectively enrolled 235 patients who had received lubiprostone at our institution from December 2012 to February 2014. The research and ethics committee of Kunimoto Hospital approved this study, and all patients provided written informed consent prior to participation. Inclusion criteria were as follows: Japanese male and female patients aged $>20$ years with CC. All patients were diagnosed with constipation as defined by the Rome III criteria [7], with decreased frequency of bowel movements (less than three times per week), a sensation of incomplete emptying, hard stools, or a history of difficult evacuation on at least a quarter of occasions. To focus exclusively on the impact of $\mathrm{CC}$ and avoid any contribution from related gastrointestinal comorbidities, all patients with irritable bowel syndrome, frequent diarrhea, Crohn's disease, or ulcerative colitis were excluded from the study.

Each of the 235 patients was treated orally with a $24 \mu \mathrm{g}$ lubiprostone capsule twice a day. The medication was taken with food and at least one glass of water. Seventy-one of the 235 patients, who were treated at a latter period (after August 2013), received a prophylactic oral dose of itopride hydrochloride (50 mg tablet twice a day before meals) together with lubiprostone to prevent nausea. Thus, the 235 patients were divided into two groups: those who received lubiprostone alone (control group; $n=164$ ) and those who received combination therapy with lubiprostone and itopride (itopride group; $n=71$ ).

The severity of constipation was quantified based on the constipation scoring system [8] (CSS; range: 0 - 30 in increments of 1 ; no symptoms $=0$ ). The following parameters were monitored on a daily basis for one week: the number of bowel movements; difficulty in evacuation; feeling of incomplete evacuation; abdominal pain; time in the lavatory; the use of laxatives, enemas, and digital assistance; failed attempts at bowel movement; and duration of constipation. The total CSS score was obtained by adding the scores of these eight individual parameters. The changes in the CSS score before and two weeks after the administration were recorded and analyzed.

Efficacy measures included change in CSS score, incidence of treatment-related adverse events including nausea, and percentage of treatment discontinuation in the first two weeks after administration.

Statistical analysis was performed using SPSS 16.0 for Windows XP (SPSS Inc., Chicago, IL, USA). Numeric variables were expressed as mean \pm standard deviation. Data were compared using the Chi square test or the Wilcoxon signed-rank test. A p-value $<0.05$ was considered statistically significant.

\section{Results}

As shown in Table 1, baseline characteristics were similar between the two groups. However, the percentage of women was significantly higher in the itopride group than in the control group $(\mathrm{p}=0.002)$. Of the 235 patients who were enrolled, 32 in the control group and 7 in the itopride group did not visit our outpatient clinic after receiving the study drugs, resulting in 196 patients available for analysis.

The changes in the CSS score from baseline to two weeks after the initiation of treatment are shown in Table

2. The patients in both treatment groups experienced statistically significant improvements in the CSS score 
Table 1. Patient demographics.

\begin{tabular}{ccc}
\hline Characteristics & Control group $(n=164)$ & Itopride group $(n=71)$ \\
\hline Gender, $n(\%)$ & & $18(25.4)$ \\
Men & $77(47.0)$ & $53(74.6)$ \\
Women & $87(53.0)$ & $65.8(17.7)$ \\
Mean age (SD), years & $64.9(18.5)$ & $13(18.3)$ \\
Age, years, $n(\%)$ & & $10(14.1)$ \\
$20-44$ & $32(19.5)$ & $48(67.6)$ \\
$45-64$ & $21(12.8)$ & $10.8 \pm 4.3$ \\
$\geq 65$ & $111(67.7)$ & $9.2 \pm 4.6$ \\
\hline
\end{tabular}

$\mathrm{SD}=$ Standard deviation; $\mathrm{CSS}=$ Constipation scoring system.

Table 2. Change in the constipation scoring system score.

\begin{tabular}{ccc}
\hline Treatment group & $n$ & Mean \pm SD \\
\hline Control group & & $9.23 \pm 4.57$ \\
Baseline & 127 & $7.29 \pm 0.41$ \\
After 2 weeks & $100^{\mathrm{a}}$ & $2.40 \pm 0.31 \quad \mathrm{p}<0.0001$ \\
Change from baseline & $100^{\mathrm{a}}$ & $10.8 \pm 4.30$ \\
Itopride group & & $8.00 \pm 0.55$ \\
Baseline & 64 & $2.61 \pm 0.33$ \\
After 2 weeks & $57^{\mathrm{a}}$ & $57^{\mathrm{a}}$ \\
\hline
\end{tabular}

${ }^{\mathrm{a}}$ Some questionnaires were returned with incomplete portions. SD = Standard deviation.

compared with baseline. The mean magnitude of alleviation was similar between the two groups $(2.40 \pm 0.31$ in the control group versus $2.61 \pm 0.33$ in the itopride group).

Among the 196 patients who took at least one dose of the study drugs, 68 (34.7\%) experienced at least one adverse event. There were no serious adverse events associated with the study drugs, and no patient deaths during the study. Adverse events occurring in $\geq 1 \%$ of patients in either of the treatment groups are listed in Table 3 . The percentage of patients who reported $\geq 1$ adverse event was significantly higher in the control group (40.9\%) than in the itopride group $(21.9 \%)(\mathrm{p}=0.008)$. Adverse events reported by $\geq 5 \%$ of patients overall were nausea $(18.4 \%)$ and diarrhea $(12.8 \%)$. In the itopride group, the percentage of patients experiencing nausea was statisticallyand significantly lower than that in the control group $(9.4 \%$ versus $22.7 \%)(\mathrm{p}=0.039)$. The percentage of patients experiencing diarrhea was also lower in the itopride group, but this finding did not reach statistical significance. With regard to the endpoint of treatment discontinuation, the itopride regimen was statistically superior compared to the control regimen $(\mathrm{p}<0.001)$.

\section{Discussion}

Our results suggest that the prophylactic administration of itopride can decrease the risk of nausea in patients receiving lubiprostone and consequently reduce the risk of treatment discontinuation.

Lubiprostone selectively stimulates type 2 chloride channels in the cells of the epithelium, which leads to an efflux of chloride into the intestinal lumen. As a result, fluid secretion into the gastrointestinal lumen initiates a bolus effect that softens stool, enhances intestinal transit, and alleviates symptoms of constipation [9].

In the current study, as well as in previous investigations, nausea is the most common adverse event. While the mechanism underlying the development of nausea in patients treated with lubiprostone is unknown, theories include an exaggerated pharmacodynamic effect from secreted fluids in the small intestine or a direct gastric effect [6]. The direct gastric effect is supported by the results of a study in normal volunteers indicating that treatment with lubiprostone resulted in a modest delay in gastric emptying [10]. However, there is currently no evidence to support a cause and effect relationship between changes in gastric emptying and symptoms of nausea [6].

Lubiprostone use is limited by the incidence of gastrointestinal adverse effects, notably nausea, which can only in part be modulated by dose reduction [11]. Prophylactic therapy of lubiprostone-induced nausea has not 
Table 3. Summary of adverse events.

\begin{tabular}{|c|c|c|c|}
\hline Adverse event, $n(\%)$ & Control group $(n=132)$ & Itopride group $(n=64)$ & p-value \\
\hline At least one adverse event & $54(40.9)$ & $14(21.9)$ & 0.008 \\
\hline Discontinued due to adverse events & $37(26.5)$ & $4(6.3)$ & $<0.001$ \\
\hline \multicolumn{4}{|l|}{ Common adverse events ${ }^{\mathrm{a}}$} \\
\hline Nausea & $30(22.7)$ & $6(9.4)$ & 0.039 \\
\hline Diarrhea & $21(15.9)$ & $4(6.3)$ & 0.094 \\
\hline Abdominal pain & $6(4.5)$ & $2(3.1)$ & 0.931 \\
\hline Vomiting & $3(2.3)$ & $0(0.0)$ & 0.552 \\
\hline Chest pain & $2(1.5)$ & $1(1.6)$ & 0.552 \\
\hline Dyspepsia & $2(1.5)$ & $1(1.6)$ & 0.552 \\
\hline Dyspnea & $2(1.5)$ & $1(1.6)$ & 0.552 \\
\hline Flatulence & $1(0.8)$ & $1(1.6)$ & 0.817 \\
\hline Dizziness & $1(0.8)$ & $1(1.6)$ & 0.817 \\
\hline
\end{tabular}

${ }^{a} \geq 1 \%$ in at least one treatment group.

been reported. We choose itopride for the prevention of lubiprostone-induced nausea because it exerts antiemetic actions through the antagonistic action of its dopamine D2 receptor. Itopride inhibits the dopamine D2 receptor at the parasympathetic nerve endings and thereby increases the release of, and decreases the metabolism of acetylcholine by inhibiting the enzyme acetylcholinesterase. By maintaining higher acetylcholine levels, itopride increases esophageal and gastrointestinal peristalsis, increases the lower esophageal sphincter pressure, stimulates gastric motility, accelerates gastric emptying, and improves gastroduodenal coordination [12]. In addition, as compared with other dopamine receptor antagonists, itopride causes a much lower incidence of central nervous system-related adverse drug reactions and hyperprolactinemia, while keeping dopamine active [13].

The most common side effects of itopride include mild to moderate abdominal pain and diarrhea [12]. Therefore, we were concerned that these adverse events would be exacerbated by administration of itopride. However, on the contrary, the incidence of both abdominal pain and diarrhea showed a slightly decreasing trend in patients who received itopride.

\section{Conclusion}

We found that the prevalence of nausea was significantly lower in the group of patients receiving itopride with lubiprostone than that in the group receiving lubiprostone alone. There were no significant differences in CSS score changes or incidence of other adverse events between the two groups. We conclude that prophylactic therapy with itopride is highly efficacious and safe for the prevention of nausea in patients taking lubiprostone.

\section{References}

[1] Lembo, A. and Camilleri, M. (2003) Chronic constipation. The New England Journal of Medicine, 349, 1360-1368. http://dx.doi.org/10.1056/nejmra020995

[2] Johanson, J.F. and Kralstein, J. (2007) Chronic Constipation: A Survey of the Patient Perspective. Alimentary Pharmacology \& Therapeutics, 25, 599-608. http://dx.doi.org/10.1111/j.1365-2036.2006.03238.x

[3] Johanson, J.F. and Ueno, R. (2007) Lubiprostone, a Locally Acting Chloride Channel Activator, in Adult Patients with Chronic Constipation: A Double-Blind, Placebo-Controlled, Dose-Ranging Study to Evaluate Efficacy and Safety. Alimentary Pharmacology \& Therapeutics, 25, 1351-1361. http://dx.doi.org/10.1111/j.1365-2036.2007.03320.x

[4] Johanson, J.F., Morton, D., Geenen, J. and Ueno, R. (2008) Multicenter, 4-Week, Double-Blind, Randomized, Placebo-Controlled Trial of Lubiprostone, a Locally-Acting Type-2 Chloride Channel Activator, in Patients with Chronic Constipation. The American Journal of Gastroenterology, 103, 170-177. http://dx.doi.org/10.1111/j.1572-0241.2007.01524.x

[5] McKeage, K., Plosker, G.L. and Siddiqui, M.A. (2006) Lubiprostone. Drugs, 66, 873-879. http://dx.doi.org/10.2165/00003495-200666060-00015

[6] Barish, C.F., Drossman, D., Johanson, J.F. and Ueno, R. (2010) Efficacy and Safety of Lubiprostone in Patients with Chronic Constipation. Digestive Diseases and Sciences, 55, 1090-1097. http://dx.doi.org/10.1007/s10620-009-1068-x

[7] Longstreth, G.F., Thompson, W.G., Chey, W.D., Houghton, L.A., Mearin, F. and Spiller, R.C. (2006) Functional Bowel Disorders. Gastroenterology, 130, 1480-1491. http://dx.doi.org/10.1053/i.gastro.2005.11.061 
[8] Agachan, F., Chen, T., Pfeifer, J., Reissman, P. and Wexner, S.D. (1996) A Constipation Scoring System to Simplify Evaluation and Management of Constipated Patients. Diseases of the Colon Rectum, 39, 681-685. http://dx.doi.org/10.1007/BF02056950

[9] Lacy, B.E. and Levy, L.C. (2008) Lubiprostone: A Novel Treatment for Chronic Constipation. Journal of Clinical Interventions in Aging, 3, 357-364.

[10] Camilleri, M., Bharucha, A.E., Ueno, R., Burton, D., Thomforde, G.M., Baxter, K., McKinzie, S. and Zinsmeister, A.R. (2006) Effect of a Selective Chloride Channel Activator, Lubiprostone, on Gastrointestinal Transit, Gastric Sensory, and Motor Functions in Healthy Volunteers. American Journal of Physiology-Gastrointestinal and Liver Physiology, 290, G942-G947. http://dx.doi.org/10.1152/ajpgi.00264.2005

[11] Gras-Miralles, B. and Cremonini, F. (2013) A Critical Appraisal of Lubiprostone in the Treatment of Chronic Constipation in the Elderly. Journal of Clinical Interventions in Aging, 8, 191-200.

[12] Huang, X., Zhang, S., Fan, Y.H. and Meng, L.N. (2012) Itopride Therapy for Functional Dyspepsia: A Meta-Analysis. World Journal of Gastroenterology, 18, 7371-7377. http://dx.doi.org/10.3748/wig.v18.i48.7371

[13] Suzuki, H., Nishizawa, T. and Hibi, T. (2006) Therapeutic Strategies for Functional Dyspepsia and the Introduction of the Rome III Classification. Journal of Gastroenterology, 41, 513-523. http://dx.doi.org/10.1007/s00535-006-1847-5 
Scientific Research Publishing (SCIRP) is one of the largest Open Access journal publishers. It is currently publishing more than 200 open access, online, peer-reviewed journals covering a wide range of academic disciplines. SCIRP serves the worldwide academic communities and contributes to the progress and application of science with its publication.

Other selected journals from SCIRP are listed as below. Submit your manuscript to us via either submit@scirp.org or Online Submission Portal.
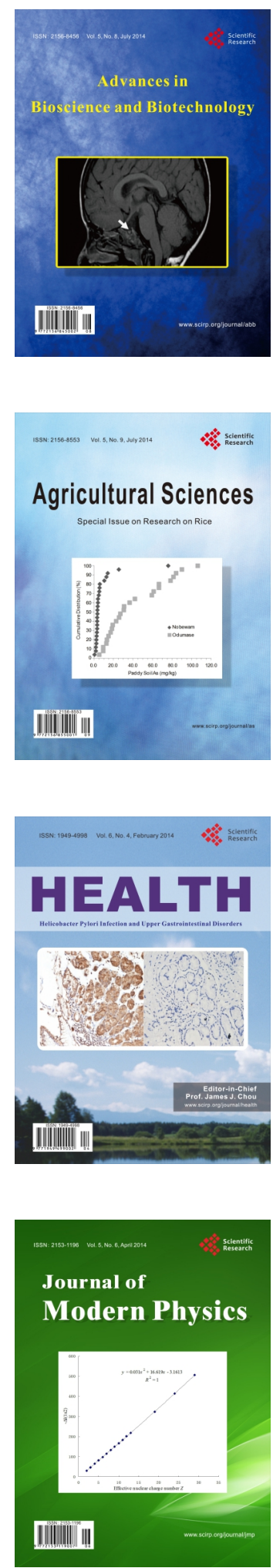
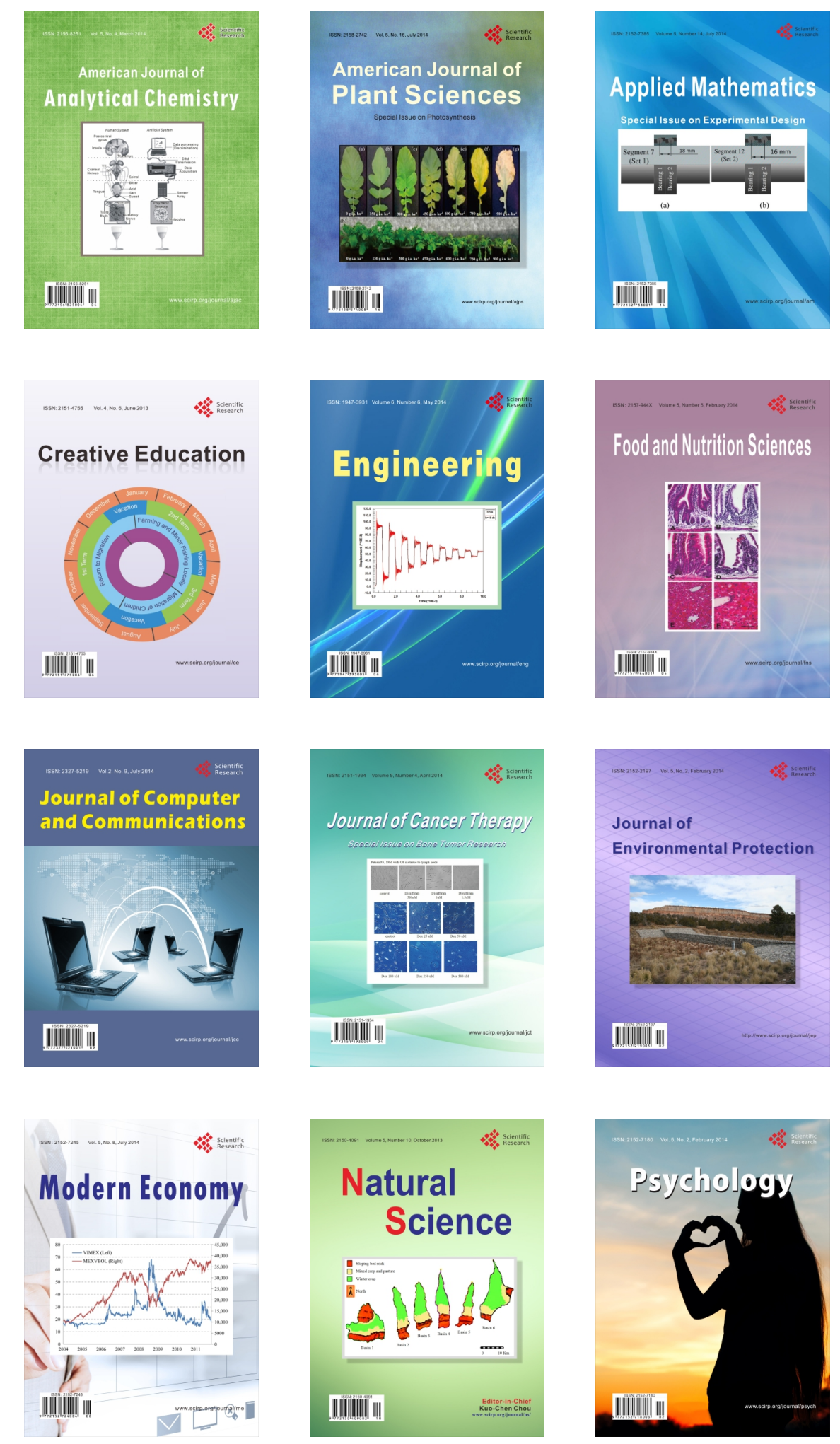